\title{
Perivascular epithelioid cell (PEC) tumors of the uterus: a clinicopathologic study of two cases with aggressive features
}

\author{
Luisanna Bosincu ${ }^{1}$, Paolo C Rocca ${ }^{1}$, Guido Martignoni ${ }^{1}$, Francisco F Nogales ${ }^{2}$, \\ Lucia Longa $^{3}$, Antonio Maccioni ${ }^{4}$ and Giovannino Massarelli ${ }^{1}$ \\ ${ }^{1}$ Anatomia Patologica, Università di Sassari, Sassari, Italy; ${ }^{2}$ Department of Pathology, University of Granada, \\ Granada, Spain; ${ }^{3}$ CNR Centro di Immunogenetica ed Oncologia Sperimentale and Dipartimento di Genetica, \\ Biologia e Chimica Medica, Università di Torino, Torino, Italy and ${ }^{4}$ Anatomia Patologica, Ospedale \\ Santissima Trinità, Cagliari, Italy
}

\begin{abstract}
We report the clinicopathologic, immunohistochemical and ultrastructural features of two unusual tumors of the uterus composed of spindle and epithelioid cells strongly positive for HMB45. The two patients of $\mathbf{5 6}$ and $\mathbf{4 8}$ years of age had, respectively, hemoperitoneum and abnormal uterine bleeding. Morphologically, both tumors showed atypia and extensive necrosis. The neoplastic cells express immunohistochemically both melanogenesis (HMB45) and smooth muscle markers (actin). Ultrastructural analysis showed the presence of intracytoplasmic membrane-bound granules. We viewed these neoplasms as perivascular epithelioid cell (PEC) tumors with aggressive features. Follow-up has shown the death of one patient whereas the other is alive without disease 36 months after the surgery. The two patients were evaluated for signs of tuberous sclerosis complex, and findings were negative.
\end{abstract}

Modern Pathology (2005) 18, 1336-1342. doi:10.1038/modpathol.3800433; published online 13 May 2005

Keywords: uterus; malignant tumor; PEComa; lymphangioleiomyomatosis; clear cell ('sugar') tumor; tuberous sclerosis

The recent literature has paid considerable attention to tumors exhibiting an immunophenotype consistent with a perivascular epithelioid cell (PEC) differentiation ${ }^{1}$ characterized by actin and HMB45 immunoreactivity and its association with the tuberous sclerosis complex (TSC). ${ }^{2}$ These neoplasms have a broad spectrum of morphology and behavior and may involve the kidney, lung, liver, pancreas, common bile duct, jejunum, rectum, falciform ligament of the liver, heart, urinary bladder, prostate, breast, bone, soft tissues ${ }^{3-10}$ and female genital tract organs, ${ }^{11,8}$ among which the uterus is the most frequently involved..$^{3,4,12-19}$ In this site, most of these tumors are benign or of uncertain malignant potential,,13,16,19 although rare malignant cases have been reported. . $^{32,14,15,17,18}$

We report the clinicopathologic features of two perivascular epithelioid cell tumors ('PEComa')

Correspondence: Dr PC Rocca, MD, Anatomia Patologica, Università di Sassari, Via G. Matteotti 58, 07100, Sassari, Italy.

E-mail: rocco@uniss.it

Received 15 November 2004; revised and accepted 22 March 2005; published online 13 May 2005 of the uterus with aggressive features, including one malignant and one with uncertain malignant potential.

\section{Case reports}

Case 1

A 59-year-old female without clinical or family history of TSC was admitted to the hospital for abdominal pain and hemorrhagic shock. Abdominal ultrasonography revealed the presence of a uterine tumor. Surgical findings included evidence of uterine rupture and hemoperitoneum with some necrotic neoplastic fragments free in the abdominal cavity. The patient was treated with total abdominal hysterectomy, bilateral salphingo-oophorectomy and omentectomy. Exploration of the upper abdominal cavity was negative. At 6 months after surgery, the tumor recurred as a $5 \mathrm{~cm}$ left pelvic mass and a fine-needle biopsy of the lesion was performed. At 1 year after diagnosis, the patient developed neoplastic cachexia and died. Autopsy was not performed. 


\section{Case 2}

A 48-year-old female without clinical or family history of TSC with frequent menometrorrhagia, which was considered due to a leiomyomatous uterus on the base of clinical and ultrasonographic findings. Endometrial curettage was unremarkable. Subsequently, the patient underwent therapy with $\mathrm{GnRH}$ analogues for 9 months and 3 months later she was readmitted to the hospital because of a further vaginal bleeding and a total abdominal hysterectomy was performed. Tamoxifen therapy was performed and the patient is alive and well without evidence of disease 36 months after surgery.

\section{Materials and methods}

\section{Histopathology and Immunohistochemistry}

The two cases we describe are from the files of the Istituto di Anatomia Patologica of Sassari University, Italy. Tissue specimens were fixed in formalin $(10 \%)$ for $24-48 \mathrm{~h}$ and routinely processed for paraffin embedding. The original sections were examined, and new sections were prepared from the blocks and stained with hematoxylin-eosin and immunohistochemically with the avidin-biotin method and a panel of antibodies recognizing the following molecules: vimentin (Amersham, Buckinghamshire, England; dilution 1:10), CD34 (Biogenex; 1:50), CD31 (Dakopatts; Denmark, 1:60), cytokeratin AE1/AE3 (Boehringer, Mannheim, Germany; 1:500), cytokeratin CAM5.2 (Becton Dickinson, Mountain View, CA, USA; 1:10), Epithelial Membrane Antigen (EMA) (Dakopatts; Denmark, 1:100), Chromogranin (Dakopatts; Denmark, 1:300), HMB-45 (gp100 protein; Dakopatts; Denmark, 1:40), Melan A (Dakopatts; Denmark 1:25), S100 protein (Dakopatts; Denmark, 1:500), Calretinin (Swant; Switzerland, 1:4000), desmin (D33; Dakopatts; Denmark, 1:500), smooth muscle actin (1A4; Dakopatts; Denmark, 1:100), estrogen receptor (Abbot Lab, Wiesbaden, Germany, undiluted) and progesterone receptor (Abbot Lab, Wiesbaden, Germany, 1:5).

Sections of the two tumors were immunostained using multiple marker procedures. They were consecutively tested for HMB45 and actin and for Melan $\mathrm{A}$ and CD34, utilizing double peroxidase immunostaining, followed by alkaline-phosphatase immunostaining.

A total of 34 mesenchymal tumors of the uterus from the files of the Istituto di Anatomia Patologica of Sassari University were compared with the study tumors.

\section{Ultrastructure}

Formalin-fixed tissue from case 2 was washed extensively in phosphate buffer, fixed in $2 \%$ glutaraldehyde in phosphate buffer for $2 \mathrm{~h}$, postfixed in $1 \%$ aqueous osmium tetroxide supplemented with $1 \%$ potassiumferryanide for $1 \mathrm{~h}$, dehydrated through graded alcohols, and embedded in a mixture of Epon and Araldite.

Ultrathin sections were obtained with an Ultracut E ultramicrotome (Reichert-Jung, Wien, Austria) and diamond knife, stained with uranyl acetate and lead citrate, and evaluated with a Zeiss EM 109 (Oberkochen, Germany) electron microscope.

\section{DNA Extraction and LOH Analysis}

DNA from $5 \mu \mathrm{m}$ histologic sections of the paraffinembedded PEC tumor of the uterus of patient 2 was extracted as previously described ${ }^{20}$ (Carbonara et al, 1996). DNA from peripheral blood leucocytes was extracted according to standard methods (Sambrook and Russel, 2001). ${ }^{21}$ The chromosome 16 TSC2linked markers tested were HBAP1, D16S525, D16S3024, KG8 and D16S291 (TSC2 lays between D16S3024 and KG8). On chromosome arm 9q, the TSC1-linked markers used from centromere to telomere were D9S149, D9S2127, D9S1830 and D9S1998 (TSC1 lays between D9S1830 and D9S1998). References for the microsatellite markers used can be found in the genome data base (GDB). Polymerase chain reaction (PCR) was performed by using fluorescent primers. In all, $5 \mu \mathrm{l}$ aliquots were amplified in a $30 \mu \mathrm{l}$ reaction containing $10 \mathrm{mM}$ Tris, $\mathrm{pH} 8.3,50 \mathrm{mM} \mathrm{KCl}, 200 \mu \mathrm{M}$ of dNTP, $1-2 \mathrm{mM} \mathrm{MgCl}_{2}$, 12 pmol of each primer and $1 \mathrm{U}$ AmliTaq Gold polymerase. All fluorescent PCR products were analyzed by electrophoresis on 377 automated DNA sequencer (Perkin Elmer/Applied Biosystems). Microsatellite analysis was performed using the GENSCAN software (Perkin Elmer/Applied Biosystems).

\section{Pathologic findings}

\section{Gross Pathology}

Case 1

The uterus measured $13 \times 8 \times 9 \mathrm{~cm}^{3}$ and showed a $6 \mathrm{~cm}$ ruptured subserosal mass. On cut section, the tumor was spongy, hemorrhagic, ill defined, with necrotic areas and involved the myometrium. The cervix, both ovaries and fallopian tubes were grossly unremarkable.

Case 2

The uterus measured $11 \times 9 \times 5 \mathrm{~cm}^{3}$ and displayed a polypoid, intracavitary, ulcerated, mass of $7 \mathrm{~cm}$ in diameter. On cut surface, the tumor was white-grey with central necrosis and hemorrhagic areas and infiltrating the myometrium (Figure 1). 


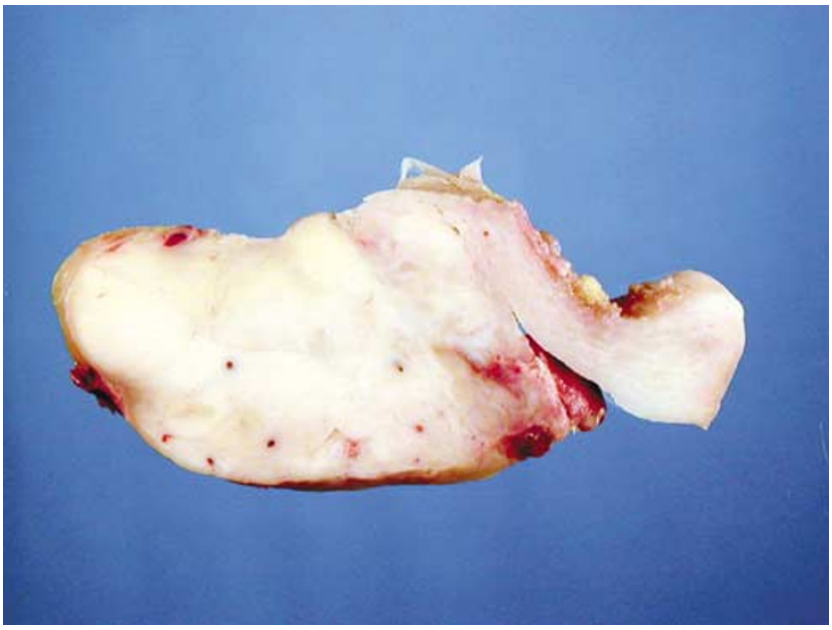

Figure 1 Grossly the tumor of case 1 was a polypoid, ulcerated mass white-gray in color.

\section{Microscopic Pathology}

Case 1

The tumor had areas of dense cellularity organized in short fascicles of epithelioid and spindle cells with a large eosinophilic or clear cytoplasm arranged around thin walled vascular structures with a prominent lymphangioleiomyomatous pattern. The nuclei of the neoplastic cells were round or oval, hyperchromatic and displayed evident nucleoli (Figure 2). Rare plurinucleated cells were seen. Mitotic figures were rare (1x10 HPF) whereas large areas of tumor cell necrosis were evident.

The fine-needle biopsy of the pelvic mass showed morphological features overlapping those of the uterine neoplasm.

\section{Case 2}

The lesion was composed of a solid epithelioid cell population showing eosinophilic cytoplasm and elongated nuclei with prominent nucleoli. Scattered plurinucleated cells were identified. Cytologic atypia, numerous mitoses ( $5 \times 10 \mathrm{HPF}$ ), infiltration of myometrium and necrotic areas were present.

\section{Immunohistochemical Findings}

Immunohistochemical results were the same for both tumors and the pelvic recurrence of case 1 . The neoplastic cells revealed a strong immunoreactivity ranging from $90 \%$ in case 1 to $30 \%$ in case 2 for HMB45, whereas Melan A was expressed in $80 \%$ of the cells of case 1 and was negative in case 2 . The immunostaining for smooth muscle actin was found in $5 \%$ of the neoplastic cells of case 1 and in $40 \%$ of case 2. The double immunostaining for HMB45 and actin highlighted the coexpression of these markers in some neoplastic cells (Figures 3 and 4). Desmin, estrogen receptors and progesterone receptors were, respectively, expressed in 10, 50 and $60 \%$ of the

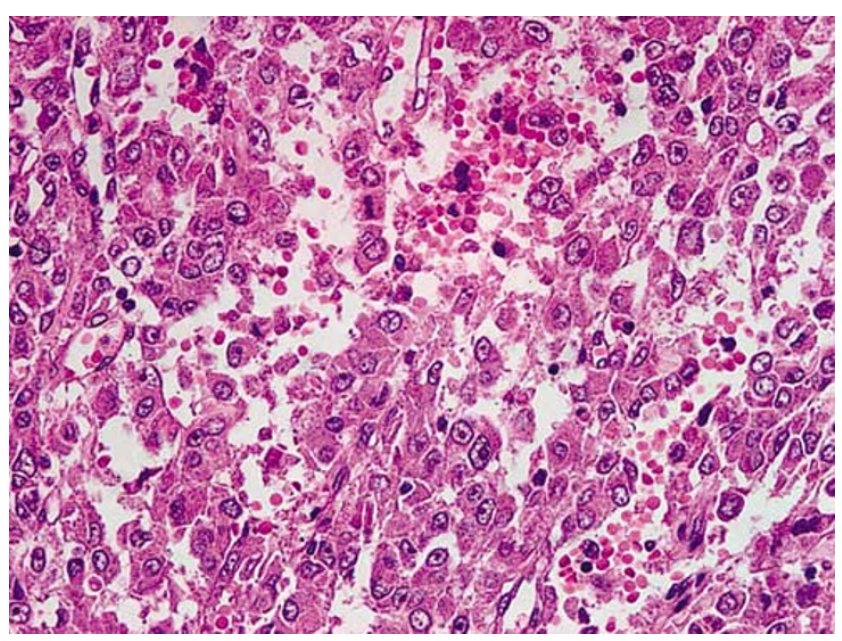

Figure 2 Case 1. Area of epithelioid cells with large eosinophilic cytoplasm and evident nucleoli.

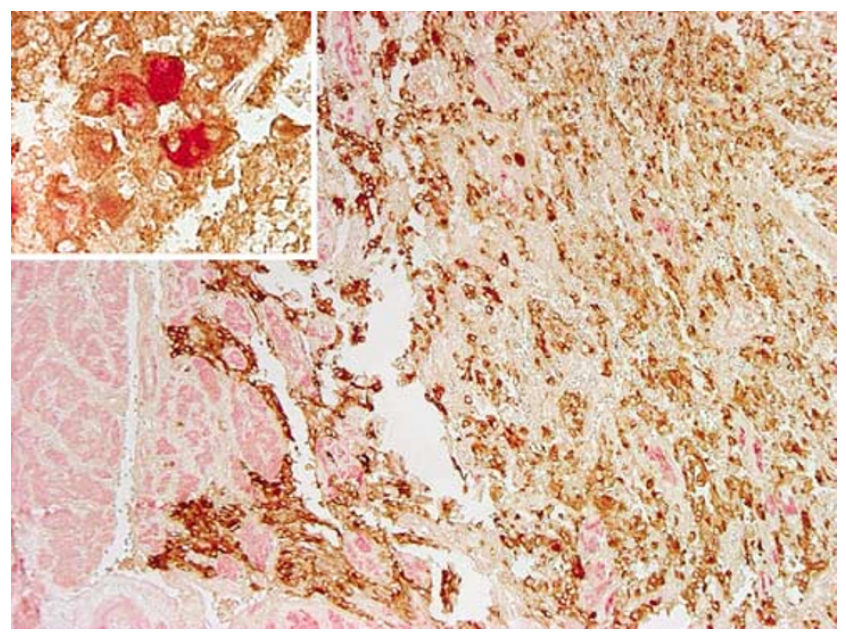

Figure 3 Case 1. A double immunostaining which showed in red (alkaline phosphatase) the actin immunoreactivity of the myometrium and in brown (peroxidase) the HMB45 granular positivity in the tumor. At high power, the coexpression of both markers in the cytoplasm of the neoplastic cells was evident (inset).

neoplastic cells of case 2, whereas AE1/AE3 and CAM 5.2 cytokeratins, EMA, chromogranin, vimentin, S100, CD31 and CD34 were consistently negative in both tumors.

The myometrium harboring the tumors was positive for actin and desmin, but negative for HMB45 and Melan A in both cases.

All the mesenchymal tumors including 16 leiomyomas (three classic, six higly cellular, two atypical, four epithelioid, one mixoid), 10 leiomyosarcomas (five classic, four mixoid, one epithelioid) and eight endometrial stromal tumors (two endometrial stromal nodules, three endometrial stromal sarcoma, low grade, two undifferentiated endometrial sarcoma and one mixed endometrial stromal and smooth muscle tumor) were negative for HMB45 immunostaining. 


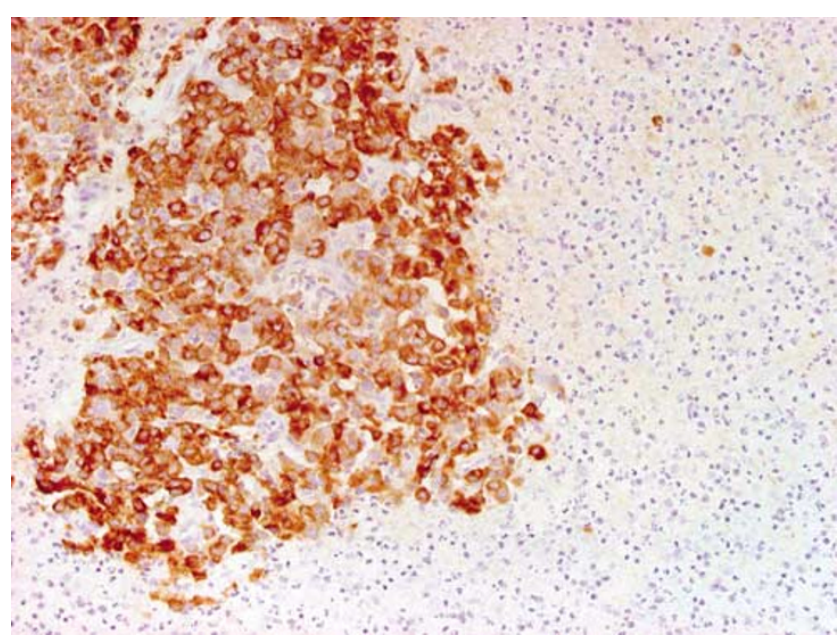

Figure 4 Fine-needle biopsy obtained from the pelvic recurrence of case 1. The HMB45 immunostaining was positive in all the fragments of the neoplastic tissue.

\section{Ultrastructural Analysis}

Ultrastructural analysis of case 2 performed in formalin-fixed material revealed the presence of numerous electron-dense, membrane-bound granules in the cytoplasm, some of which resembled premelanosomes and abundant microfilaments with dense bodies, suggesting a smooth muscle origin of the proliferating cells.

\section{Genetic Findings}

The PEC tumor of the uterus from patient 2 was analyzed for loss of heterozygosity at TSC1 and TSC2-linked markers. DNA extracted from peripheral blood leucocytes and from normal endometrium was available as control of the germline genotype. All microsatellites analyzed on $16 \mathrm{p}$ were informative. No LOH was observed either at the TSC1 or at the TSC2 locus.

\section{Discussion}

The 'perivascular epithelioid cell' (PEC) is the descriptive term, first proposed by Bonetti et $a l^{1}$ to identify a 'novel' cell type, which coexpresses melanogenesis and smooth muscle markers. Neoplasms with perivascular epithelioid cell differentiation are called PEComas and are defined as mesenchymal tumors composed of histologically and immunohistochemically distinctive perivascular epithelioid cells. ${ }^{22,23}$ This family of tumors includes renal and extrarenal angiomyolipoma, ${ }^{23,9,5-7}$ pulmonary and extrapulmonary clear cell 'sugar' tumor ${ }^{25,4,8,10}$ pulmonary and extrapulmonary lymphangioleiomyomatosis, ${ }^{25-27}$ clear cell myomelanocytic tumor of ligamentum teres ${ }^{4}$ and abdominopelvic sarcoma of PEC. ${ }^{3}$ Recently, these tumors have been also described in the breast, urinary bladder, prostate gland, jejunum, common bile duct and in the soft tissues of the thigh. ${ }^{4}$

PEC proliferations can rarely involve the female genital tract. The first case reported by Pea et $a l^{16}$ was a polypoid tumor involving the endometrium, which showed morphological features closely related to the clear cell 'sugar' tumor of the lung. Vang and Kempson ${ }^{19}$ described eight examples of uterine perivascular epithelioid cell tumor ('PEComa') distinguishing a morphologic spectrum of neoplasms varying from tumors with a tongue-like growth pattern composed of sheets of HMB45-positive clear epithelioid cells, which they called group A, to circumscribed tumors composed of hyalinized stroma and neoplastic cells focally positive for HMB45 and extensively immunoreactive for actin and desmin, which they referred to as group B. A tumor with a strong and diffuse HMB45 expression morphologically corresponding to an epithelioid angiomyolipoma has been reported in the ovary. ${ }^{11}$ Finally, one case described as primary extrapulmonary sugar tumor of the vulva has been reported by Tazelaar et $a l^{8}$ Lesions considered to be uterine involvement of lymphangioleiomyomatosis were usually asymptomatic and some of them corresponded to an incidental finding in patients bearing stigmata of TSC. ${ }^{28-30}$

The spectrum of the morphological features of the neoplasms with perivascular epithelioid cell differentiation is very broad with a great variation in the relative proportion of spindle and epithelioid cells arranged in a perivascular location with a solid or a lymphangioleiomyomatous pattern. Both patterns of growth have been described in tumors arising in the uterus. ${ }^{15,17,19}$ The perivascular epithelioid cell tumors of the uterus have usually shown benign behavior. ${ }^{13,16,19}$ but eleven tumors, two of them associated with TSC, were aggressive (Table 1).

We consider our two cases as PEComas since one of them exhibited a lymphangioleiomyomatous architecture and the other had an ultrastructural evidence of electron-dense membrane-bound granules associated with smooth muscle differentiation, characteristic of perivascular epithelioid cells. Moreover, both neoplasms were immunoreactive for HMB45 and actin. Both tumors showed aggressive histologic features such as severe cytologic atypia, the mitotic activity (case 2) and the large necrotic areas. We view case 1 as malignant because of the recurrences and death due to the disease, whereas we define case 2 as PEComa with uncertain malignant potential because of the aggressive histologic features previously described.

In regard to morphologic criteria of malignancy in PEComas, some features such as nuclear atypia, number of mitoses and presence of necrosis have been taken into consideration, although none of them seem to be significantly related to malignant behavior. Folpe et $a l^{12}$ reported 24 cases of PEComas of soft tissues and gynecologic origin, 
Table 1 Review of literature of malignant PEC tumors of the uterus

\begin{tabular}{|c|c|c|c|c|c|c|c|}
\hline Cases & $\begin{array}{c}\text { Age } \\
\text { (years) }\end{array}$ & Symptoms & Site & Histology & TSC & Treatment & Follow-up \\
\hline Gyure (95) & 29 & Pelvic mass & Myometrium & LAM-like & + & $\mathrm{S}, \mathrm{CH}, \mathrm{RT}$ & $\begin{array}{l}\text { Died for metastatic } \\
\text { ovarian carcinoma, } \\
12 \text { mo }\end{array}$ \\
\hline Ruco (98) & 56 & Abdominal pain & $\begin{array}{l}\text { Myometrium and right } \\
\text { ovary }\end{array}$ & LAM-like & - & $S$ & $\begin{array}{l}\text { Alive with local } \\
\text { recurrence, } 84 \text { mo }\end{array}$ \\
\hline Bonetti (01) & 19 & Abdominal pain & Lower uterine segment & Epithelioid & - & $\mathrm{S}, \mathrm{CH}, \mathrm{RT}$ & NA \\
\hline Bonetti (01) & 41 & Abdominal mass & $\begin{array}{l}\text { Subserosal } \\
\text { myometrium }\end{array}$ & Epithelioid & + & S & NED, 6 mo \\
\hline Dimmler (03) & 61 & $\begin{array}{l}\text { Abnormal uterine } \\
\text { bleeding }\end{array}$ & $\begin{array}{l}\text { Subserosal } \\
\text { myometrium }\end{array}$ & Epithelioid & - & $S$ & $\begin{array}{l}\text { Alive with lung } \\
\text { metastases, } 84 \text { mo }\end{array}$ \\
\hline Greene (03) & 79 & Abdominal pain & $\begin{array}{l}\text { Uterine fundus and } \\
\text { pelvis }\end{array}$ & Epithelioid & - & $\mathrm{S}, \mathrm{CH}$ & $\begin{array}{l}\text { Local recurrence and } \\
\text { DOD, } 24 \text { mo }\end{array}$ \\
\hline Silva (04) & 82 & $\begin{array}{l}\text { Abdominal pain, } \\
\text { vaginal bleeding }\end{array}$ & Uterus and pelvis & Epithelioid & - & $S$ & DOD 32 mo \\
\hline Silva (04) & 47 & $\begin{array}{l}\text { Abnormal uterine } \\
\text { bleeding }\end{array}$ & Uterus & Epithelioid & - & $\mathrm{S}, \mathrm{CH}, \mathrm{RT}$ & $\begin{array}{l}\text { Lung metastases and } \\
\text { DOD, } 30 \text { mo }\end{array}$ \\
\hline Silva (04) & 76 & Pelvic mass & $\begin{array}{l}\text { Subserosal } \\
\text { myometrium and } \\
\text { pelvis }\end{array}$ & Epithelioid & - & $\mathrm{S}, \mathrm{RT}$ & $\mathrm{NED}, 8 \mathrm{mo}$ \\
\hline Silva (04) & 73 & Abdominal pain & Uterus & Epithelioid & - & $\mathrm{S}, \mathrm{CH}$ & $\begin{array}{l}\text { Lung metastases and } \\
\text { DOD, } 9 \text { mo }\end{array}$ \\
\hline Silva (04) & 43 & $\begin{array}{l}\text { Abnormal uterine } \\
\text { bleeding }\end{array}$ & Uterus & Epithelioid & - & $\mathrm{S}, \mathrm{CH}$ & $\begin{array}{l}\text { Alive with lung } \\
\text { metastases, } 6 \text { mo }\end{array}$ \\
\hline Present & 56 & Hemoperitoneum & $\begin{array}{l}\text { Subserosal } \\
\text { myometrium }\end{array}$ & LAM-like & - & $\mathrm{S}$ & $\begin{array}{l}\text { Local recurrence and } \\
\text { DOD, } 12 \text { mo }\end{array}$ \\
\hline Present & 48 & $\begin{array}{l}\text { Abnormal uterine } \\
\text { bleeding }\end{array}$ & $\begin{array}{l}\text { Subendometrial } \\
\text { myometrium }\end{array}$ & Epithelioid & - & $\mathrm{S}, \mathrm{TX}$ & NED,36 months \\
\hline
\end{tabular}

TSC = tuberous sclerosis complex; $\mathrm{S}=$ surgical; $\mathrm{CH}=$ chemotherapy; $\mathrm{RT}=$ radio therapy; $\mathrm{TX}=$ tamoxifen; $\mathrm{NA}=$ not available; $\mathrm{DOD}=\mathrm{died}$ of disease $\mathrm{NED}=$ no evidence of disease; $\mathrm{mo}=$ months .

concluding that these tumors can be benign or malignant and their malignancy is correlated with large size in the face of any level of mitotic activity and necrosis. ${ }^{31}$

Many entities should be considered in the differential diagnosis with neoplasms with perivascular epithelioid cell differentiation of the uterus. Clear and oxyphilic carcinomas show a characteristic positivity for cytokeratins, which is absent in PEComas. Endometrial stromal sarcomas are not immunoreactive for HMB45..$^{32,19}$ Metastatic melanoma and the rare melanocytic differentiation found in carcinosarcomas ${ }^{33}$ show S100 and HMB45 positivity in contrast with PEC tumors that are negative for the S100 protein. PEComas can be difficult to differentiate from clear and epithelioid smooth muscle tumors ${ }^{34}$ but these entities are negative for HMB 45. ${ }^{19}$ Leiomyosarcoma is usually negative for estrogen and progesterone receptors, ${ }^{35}$ which can be expressed in PEComas as it occurred in our case 2.

Benign and malignant smooth muscle tumors have been described to arise spontaneously in Eker rats, which are considered the animal model of the TSC. Most of these neoplasms were typical leiomyoma whereas a subset of these were atypical showing an epithelioid morphology. ${ }^{36}$ Although more cases need to be studied, the uterine HMB45positive tumors that we describe in this study could represent the human counterpart of the leiomyoma and leiomyosarcoma of the Eker rats.

We suggest that HMB45 immunostaining should be performed on uterine mesenchymal tumors with lymphangiomyomatous pattern or with clear and epithelioid features to identify PEC tumors and we believe that their identification warrants the examination of the patient for the stigmata of TSC.

The absence of LOH for TSC1 and TSC2 gene in the neoplastic cells of the case 2 is in accord with the fact that the $50 \%$ of tumors occurring in patients with TSC are negative with this analysis ${ }^{20}$ and we think that other cases should be tested to accurately evaluate this issue.

Some authors suggest avoiding the use of the term PEComa and to maintain the old terminology, such as epithelioid leiomyosarcoma with clear cells, for practical reasons. ${ }^{18}$ We agree with them for lesions related to PEC, which have been extensively described in their clinicopathological features and are known with well-established names by clinicians and pathologists, for example, angiomyolipoma and lymphangioleiomyomatosis; however, we think that the use of the term PEComa for all the other lesions should be encouraged to try to accumulate new clinicopathologic and genetic data regarding these peculiar lesions to better define them and their relationship with TSC. 


\section{Acknowledgements}

This work was supported in part by MIUR (20022003); Fondazione Banco di Sardegna (2003). We thank Antonica Mura, Rita Bronzini and Salvatore Marceddu for their technical assistance.

\section{References}

1 Bonetti F, Pea M, Martignoni G, et al. PEC and sugar. Am J Surg Pathol 1992;16:307-308.

2 Bonetti F, Pea M, Martignoni G, et al. The perivascular epithelioid cell and related lesions. Adv Anat Pathol 1997;4:343-358.

3 Bonetti F, Martignoni G, Colato C, et al. Abdominopelvic sarcoma of perivascular epithelioid cells. Report of four cases in young women, one with tuberous sclerosis. Mod Pathol 2001;14:563-568.

4 Fadare O, Parkash V, Yilmaz Y, et al. Perivascular epithelioid cell tumor (PEComa) of the uterine cervix associated with intraabdominal 'PEComatosis': a clinicopathological study with comparative genomic hybridization analysis. World J Surg Oncol 2004;2:35.

5 Insabato L, De Rosa G, Terraciano LM, et al. Primary monotypic epithelioid angiomyolipoma of bone. Histopathology 2002;40:286-290.

6 Martignoni G, Pea M, Bonetti F, et al. Carcinomalike monotypic epithelioid angiomyolipoma in patients without evidence of tuberous sclerosis: a clinicopathologic and genetic study. Am J Surg Pathol 1998;22: 663-672.

7 Pea M, Bonetti F, Martignoni G, et al. Apparent renal cell carcinomas in tuberous sclerosis are heterogeneous: the identification of malignant epithelioid angiomyolipoma. Am J Surg Pathol 1998;22:180-187.

8 Tazelaar HD, Batts KP, Srigley JR. Primary extrapulmonary sugar tumor (PEST): a report of four cases. Mod Pathol 2001;14:615-622.

9 Yamasaki S, Tanaka S, Fujii $\mathrm{H}$, et al. Monotypic epithelioid angiomyolipoma of the liver. Histopathology 2000;36:451-456.

10 Zamboni G, Pea M, Martignoni G, et al. Clear cell ('sugar') tumor of the pancreas. A novel member of the family of lesions characterized by the presence of perivascular epithelioid cells. Am J Surg Pathol 1996; 20:722-730.

11 Anderson AE, Yang X, Young RH. Epithelioid angiomyolipoma of the ovary: a case report and literature review. Int J Gynecol Pathol 2002;21:69-73.

12 Dimmler A, Seitz G, Hohenberger W, et al. Late pulmonary metastasis in uterine PEComa. J Clin Pathol 2003;56:627-628.

13 Fukunaga M. Perivascular epithelioid cell tumor of the uterus: a case report. Int J Gynecol Pathol 2004;23: 287-291.

14 Greene LA, Mount SL, Schned AR, et al. Recurrent perivascular epithelioid cell tumor of the uterus (PEComa): an immunohistochemical study and review of the literature. Gynecol Oncol 2003;90:677-681.

15 Gyure KA, Hart WR, Kennedy AW. Lymphangiomyomatosis of the uterus associated with tuberous sclerosis and malignant neoplasia of the female genital tract: a report of two cases. Int J Gynecol Pathol 1995; 14:344-351.
16 Pea M, Martignoni G, Zamboni G, et al. Perivascular epithelioid cell. Am J Surg Pathol 1996;20:1149-1153.

17 Ruco LP, Pilozzi E, Wedard BM, et al. Epithelioid lymphangioleiomyomatosis-like tumour of the uterus in a patient without tuberous sclerosis: a lesion mimicking epithelioid leiomyosarcoma. Histopathology 1998;33:91-93.

18 Silva EG, Deavers MT, Bodurka DC, et al. Uterine epithelioid leiomyosarcomas with clear cells: reactivity with HMB-45 and the concept of PEComa. Am J Surg Pathol 2004;28:244-249.

19 Vang R, Kempson RL. Perivascular epithelioid cell tumor ('PEComa') of the uterus: a subset of HMB-45positive epithelioid mesenchymal neoplasms with uncertain relationship to pure smooth muscle tumors. Am J Surg Pathol 2002;26:1-13.

20 Carbonara C, Longa L, Grosso E, et al. Apparent preferential loss of heterozigosity at TSC2 over TSC1 chromosomal region in tuberous sclerosis hamartomas. Genes Chrom Cancer 1996;15:18-25.

21 Sambrook J, Russell DW. Molecular Cloning. A Laboratory Manual, Vol 1, 3rd edn. Cold Spring Harbor Laboratory Press: New York, 2001, Chapter 6.4-6.10.

22 Folpe AL. Neoplasms with perivascular epithelioid cell differentiation (PEComas) In: Fletcher CDM, Unni KK, Epstein J, Mertens F (eds). Pathology and Genetics of Tumours of Soft Tissue and Bone. Series: WHO Classification of tumours. IARC Press: Lyon, 2002, pp. 221-222.

23 Hendrickson MR, Tavassoli FA, Kempson RL, et al. Mesenchymal tumours and related lesions. In: Tavassoli FA, Devilee P (eds). Pathology and Genetics of Tumours of the Breast and Female Genital Organs. Series: WHO Classification of tumours. IARC Press: Lyon, 2003, pp 233-244.

24 Martignoni G, Amin M. Angiomyolipoma. In: Eble JN, Sauter G, Epstein J, Sesterhenn I (eds). Pathology and Genetics of Tumours of the Urinary System and Male Genital Organs. Series: WHO Classification of tumours. IARC Press: Lyon, 2004, pp 65-67.

25 Bonetti F, Chiodera P, Pea M, et al. Transbronchial biopsy in lymphangiomyomatosis of the lung. HMB45 for diagnosis. Am J Surg Pathol 1993;17:1092-1102.

26 Martignoni G, Bonetti F, Pea M, et al. Renal disease in adults with TSC2/PKD1contiguous gene syndrome. Am J Surg Pathol 2002;26:198-205.

27 Matsui K, Tatsuguchi A, Valencia J, et al. Extrapulmonary lymphangioleiomyomatosis (LAM): clinicopathologic features in 22 cases. Hum Pathol 2000;3: 1242-1248.

28 Kimura N, Watanabe M, Date F, et al. HMB-45 and tuberin in hamartomas associated with tuberous sclerosis. Mod Pathol 1997;10:952-959.

29 Lack EE, Dolan MF, Finisio J, et al. Pulmonary and extrapulmonary lymphangioleiomyomatosis. Report of a case with bilateral renal angiomyolipomas, multifocal lymphangioleiomyomatosis, and a glial polyp of the endocervix. Am J Surg Pathol 1986;10:650-657.

30 Torres VE, Bjornsson J, King BF, et al. Extrapulmonary lymphangioleiomyomatosis and lymphangiomatous cysts in tuberous sclerosis complex. Mayo Clin Proc 1995;70:641-648.

31 Folpe AL, Mentzel T, Lehr HA, et al. Perivascular epithelioid cell neoplasms (PEComas) of soft tissue and gynecologic origin: a clinicopathologic study of 24 cases. Mod Pathol 2005;18:48A. 
32 Itoh T, Mochizuki M, Kumazaki S, et al. Cystic pulmonary metastases of endometrial stromal sarcoma of the uterus, mimicking lymphangiomyomatosis: a case report with immunohistochemistry of HMB45. Pathol Int 1997;47:725-729.

33 Amant F, Moerman P, Davel GH, et al. Uterine carcinosarcoma with melanocytic differentiation. Int J Gynecol Pathol 2001;20:186-190.

34 Zamecnik M, Michal M. HMB45+ hyalinized epithelioid tumor of the uterus is linked to epithelioid leiomyoma rather than to PEC-omas. Int J Surg Pathol 2001;9:341-343.

35 Mittal K, Demopoulos RI. MIB-1 (Ki-67), p53, estrogen receptor, and progesterone receptor expression in uterine smooth muscle tumors. Hum Pathol 2001;32: 984-987.

36 Everitt JI, Wolf DC, Howe SR, et al. Rodent model of reproductive tract leiomyomata. Clinical and pathological features. Am J Pathol 1995;146: 1556-1567. 